\title{
Polyarteritis nodosa and bronchiolitis obliterans with organizing pneumonia, an unusual association
}

\author{
Kaberi Dasgupta MD, A Kevin Watters MD FRCPC, Arnold Zidulka MD FRCPC \\ Montreal General Hospital; and McGill University, Montreal, Quebec
}

\begin{abstract}
K Dasgupta, AK Watters, A Zidulka. Polyarteritis nodosa and bronchiolitis obliterans with organizing pneumonia, an unusual association. Can Respir J 1997;4(4):221-223. Bronchiolitis obliterans and organizing pneumonia (BOOP) is an inflammatory, fibrotic disorder of the small airways, alveoli and pulmonary intersitium. Often idiopathic and usually benign, this condition may cause dyspnea and influenza-like symptoms. Polyarteritis nodosa (PAN) is a small and medium vessel vasculitis, which usually involves the kidney and other viscera but rarely results in vasculitis of the lungs. This is the second case of BOOP associated with PAN reported in the literature. Knowledge of this association is likely to be of value because an undiagnosed vasculitis can rapidly become fatal.
\end{abstract}

Key Words: Bronchiolitis obliterans and organizing pneumonia (BOOP), Polyarteritis nodosa (PAN), Vasculitis
La périartérite noueuse associée à une bronchiolite oblitérante avec pneumonie en voie d'organisation : une association inhabituelle

RÉSUMÉ : Une bronchiolite oblitérante avec pneumonie en voie d'organisation est une atteinte fibreuse inflammatoire des petites voies aériennes, des alvéoles et de l'interstitium pulmonaire. Souvent idiopathique et bénin, cet état peut causer de la dyspnée et des symptômes ressemblant à la grippe. La périartérite noueuse est une vasculite des petits et des moyens vaisseaux, qui touche habituellement le rein et les autres viscères mais qui provoque rarement une vasculite des poumons. Il s'agit du deuxième cas de bronchiolite oblitérante avec pneumonie en voie d'organisation associée à une périartérite noueuse, rapporté dans la littérature. La connaissance d'une telle association est certainement importante puisqu'une vasculite non diagnostiquée peut rapidement devenir fatale.
$\mathrm{B}$ ronchiolitis obliterans and organizing pneumonia (BOOP) is a pathological diagnosis involving inflammation and fibrosis of small airways, adjacent alveoli and pulmonary interstitum. BOOP is usually idiopathic, but has been associated with noxious gas exposure, recent pulmonary infection, heart-lung transplantation, connective tissue disorders, chronic eosinophilic pneumonia, extrinsic allergic alveolitis and adverse drug reactions. Patients typically present with several months of dyspnea and influenza-like symptoms. The following is, to our knowledge, the second reported association of BOOP with polyarteritis nodosa (PAN). 


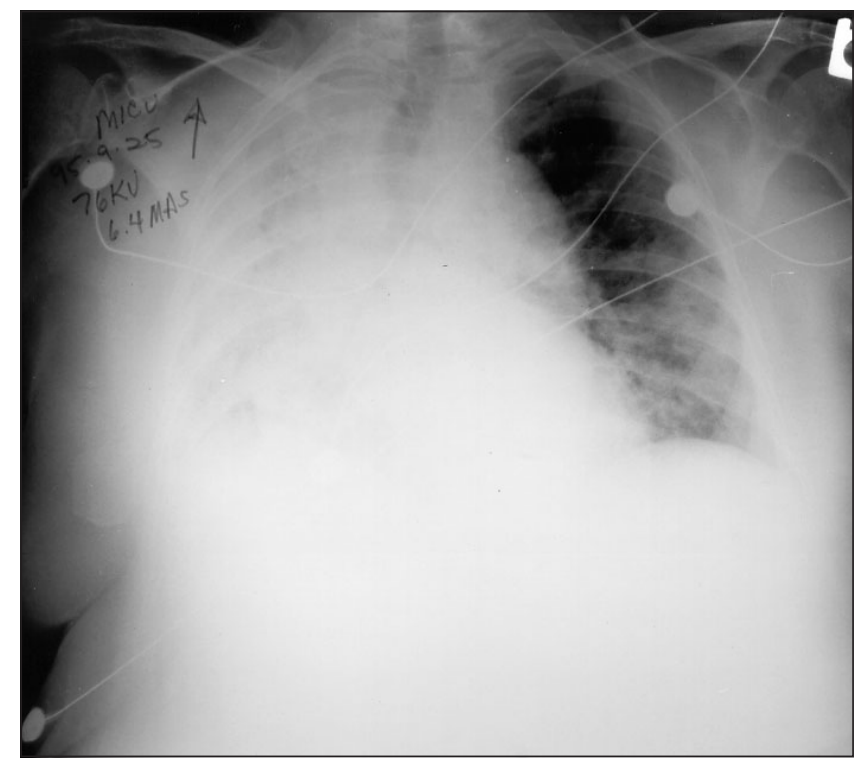

Figure 1) Chest radiograph demonstrating bilateral airspace disease

\section{CASE PRESENTATION}

A 75-year-old hospital volunteer worker was admitted to hospital with a two-week history of fever refractory to broad spectrum antibiotics. She had stopped smoking 35 years previously. History included hypertension, hypothyroidism and recurrent sinusitis. Her medications were enalapril and levothyroxine.

She had experienced four months of fatigue, two months of dyspnea and two weeks of fever $\left(38.5^{\circ} \mathrm{C}\right)$ with no clear cause of infection. She was admitted to a secondary care hospital where she remained for 17 days. A chest radiograph revealed no pneumonia. Sinus films indicated chronic left maxillary sinusitis. Various cultures were taken, and she was started on intravenous ceftriaxone.

Liver function tests were mildly elevated on admission and continued to rise over the next 10 days (lactase dehydrogenase $465 \mathrm{U} / \mathrm{L}$, aspartate aminotransferase $128 \mathrm{U} / \mathrm{L}$, alanine aminotransferase $94 \mathrm{U} / \mathrm{L}$, alkaline phosphatase $169 \mathrm{U} / \mathrm{L}$, total bilirubin $28.5 \mu \mathrm{mol} / \mathrm{L}$, direct fraction $15.4 \mathrm{mmol} / \mathrm{L}$ ). An abdominal ultrasound and an echocardiogram revealed no abnormalities.

Nine days before transfer to the Montreal General Hospital the patient had an acute decrease in hemoglobin, from $98 \mathrm{~g} / \mathrm{L}$ to $74 \mathrm{~g} / \mathrm{L}$. After transfusion with three units of packed red blood cells, she required diuresis for pulmonary edema confirmed by chest radiograph. A radiological upper and lower gastrointestinal series showed distal colonic diverticulosis. During the 17 days at the secondary care hospital, the patient's creatinine rose to $432 \mu \mathrm{mol} / \mathrm{L}$ from $156 \mu \mathrm{mol} / \mathrm{L}$ on admission.

On arrival at the Montreal General Hospital, the patient was tachypneic, with coarse crackles throughout the right lung field but a normal jugular venous pressure. Arterial blood gas on room air was $\mathrm{pH} 7.49, \mathrm{PCO}_{2} 28 \mathrm{mmHg}, \mathrm{PO}_{2} 52$ $\mathrm{mmHg}$ and bicarbonate $22 \mathrm{mM} / \mathrm{L}$. Urine microscopy revealed red cell and granular casts. Chest radiograph showed extensive right-sided airspace disease. Bronchoscopy re-

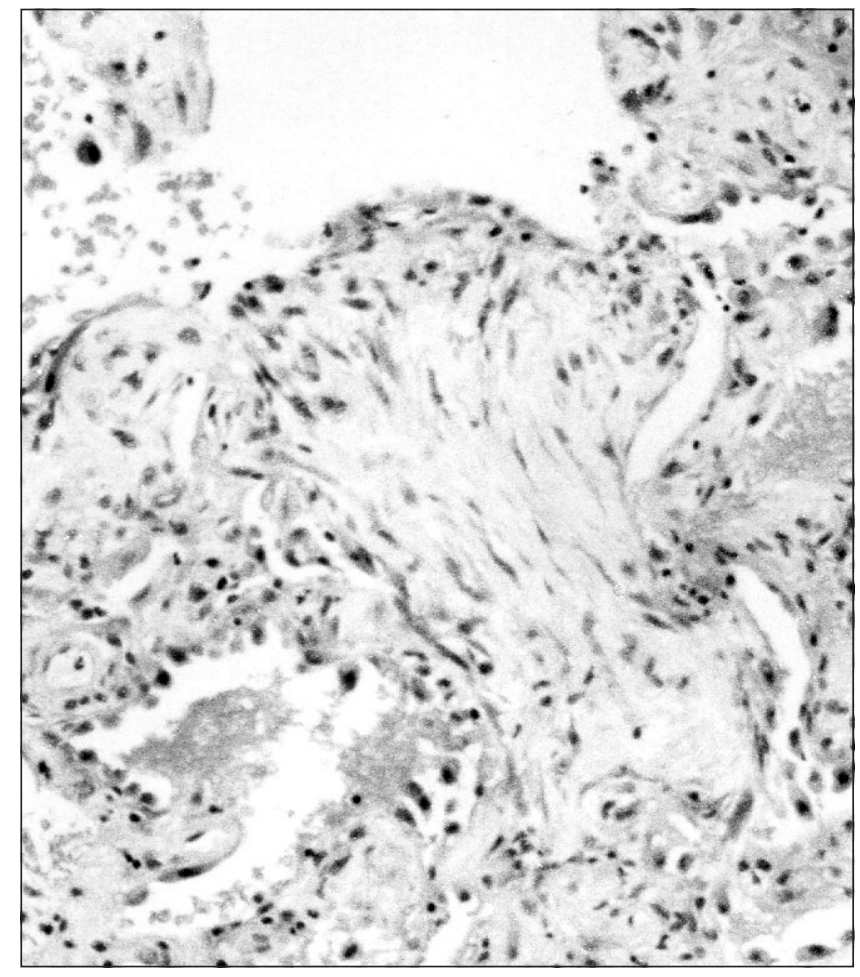

Figure 2) Bronchiolitis obliterans and organizing pneumonia with granulation tissue filling an alveolar duct (hematoxylin and eosin, original magnification $\times 600$ )

vealed only a noninflamed tracheobronchial mucosa; a transbronchial biopsy was performed.

The absence of pus on bronchoscopy and the presence of an active urinary sediment was felt to be suggestive of vasculitis; consequently, the patient received $1 \mathrm{~g}$ of methylprednisolone intravenously. However, intravenous erythromycin was started because atypical pneumonia remained in the differential diagnosis at this time. Ceftriaxone was discontinued.

Within two days of transfer, the patient became oliguric and edematous with a poor response to diuretics. Despite dialysis, her oxygen requirement increased dramatically, and she required intubation and mechanical ventilation with positive end-expiratory pressure (PEEP). Chest radiograph revealed diffuse bilateral airspace disease (Figure 1). Pulmonary artery catheterization revealed normal cardiac parameters and a wedge pressure of $14 \mathrm{mmHg}$, consistent with acute respiratory distress syndrome (ARDS).

The patient received further doses of pulse steroids and intravenous erythromycin. Continuous venovenous hemofiltration $(\mathrm{CVVH})$ was employed to decrease the wedge pressure to $10 \mathrm{~cm} \mathrm{H}_{2} \mathrm{O}$ in an attempt to decrease her forced inspiratory oxygen $\left(\mathrm{FiO}_{2}\right)$ requirement without rendering her hypotensive. All blood and sputum cultures were negative. Viral titres were unrevealing. Examination of the transbronchial biopsy showed a mild acute bronchitis with focal collections of alveolar macrophages and mild interstitial inflammation without evidence of stainable organisms or evidence of vasculitis. Serum antinuclear antibody, rheumatoid factor, antineutrophilic cytoplasmic antibody and antiglomerular 
basement membrane antibody were negative. Left inferior turbinate biopsy showed mild nonspecific inflammation.

The patient developed vaginal bleeding. Gynecological examination was unrevealing. An endometrial biopsy showed an inactive noncyclic menstrual endometrium.

An open lung biopsy (Figure 2) demonstrated focal organizing granulation tissue in alveoli, alveolar ducts and bronchioli. Interstitial inflammation and reactive bronchial and alveolar cell hyperplasia with occasional hyaline membranes without evidence of vasculitis or of microorganisms were present. These findings were felt to be consistent with BOOP. Methylprednisolone was continued, and, despite the absence of pathological evidence for vasculitis, a single dose of cyclophosphamide was administered.

Three weeks after transfer, the patient's $\mathrm{FiO}_{2}$ requirement was $100 \%$, despite CVVH, steroids, PEEP and a trial of pressure control with inverse ratio ventilation. She was in a comatose state and had become pressor-dependent. After discussion with the family, support was withdrawn, and the patient died.

At autopsy the lungs were diffusely consolidated with a total weight of $1496 \mathrm{~g}$. There was microscopic evidence of residual BOOP. In addition, there was extensive pulmonary edema and congestion with evidence of remote and acute alveolar hemorrhage with hyaline membrane formation and reactive alveolar changes present, consistent with ARDS. There was no evidence of vasculitis identified in sections of the lungs. A necrotizing arteritis of small muscular arteries was present in many organs including the pancreas (Figure 3), fallopian tubes, thyroid, cervix and kidneys, consistent with PAN. The kidneys, in addition, contained a focal segmental glomerulonephritis. There were ischemic changes present in the glomeruli and distal convoluted tubules with evidence of glomerular and tubule hemorrhage.

\section{DISCUSSION}

PAN is a vasculitis of small and medium muscular arteries that does not classically involve the lungs. This is the second case report describing a patient with polyarteitis nodosa and lung pathology characterized not by vasculitis but by BOOP. The first case report of PAN associated with BOOP (1) described a patient with a four-week history of fever and dry cough unresponsive to antibiotics and a subsequent clinical course strikingly similar to that of our patient. The authors of that case report noted that gamma interferon may be a BOOP mediator by causing airway epithelial cell class II antigen expression and a consequent autoimmune response; they determined that the gamma interferon production of their patient's bronchoalveolar lavage cells was greater than that of the cells of normal individuals (1).

Cases of Wegener's granulomatosis associated with BOOP have been reported $(2,3)$. In a clinical-pathological correlation (3), a patient with a pulmonary nodule and renal failure was described. Renal biopsy clearly demonstrated focal segmental necrotizing glomerulonephritis, typical of early Wegener's granulomatosis. The open lung biopsy, however, was not typical of Wegener's granulomatosis: areas of BOOP

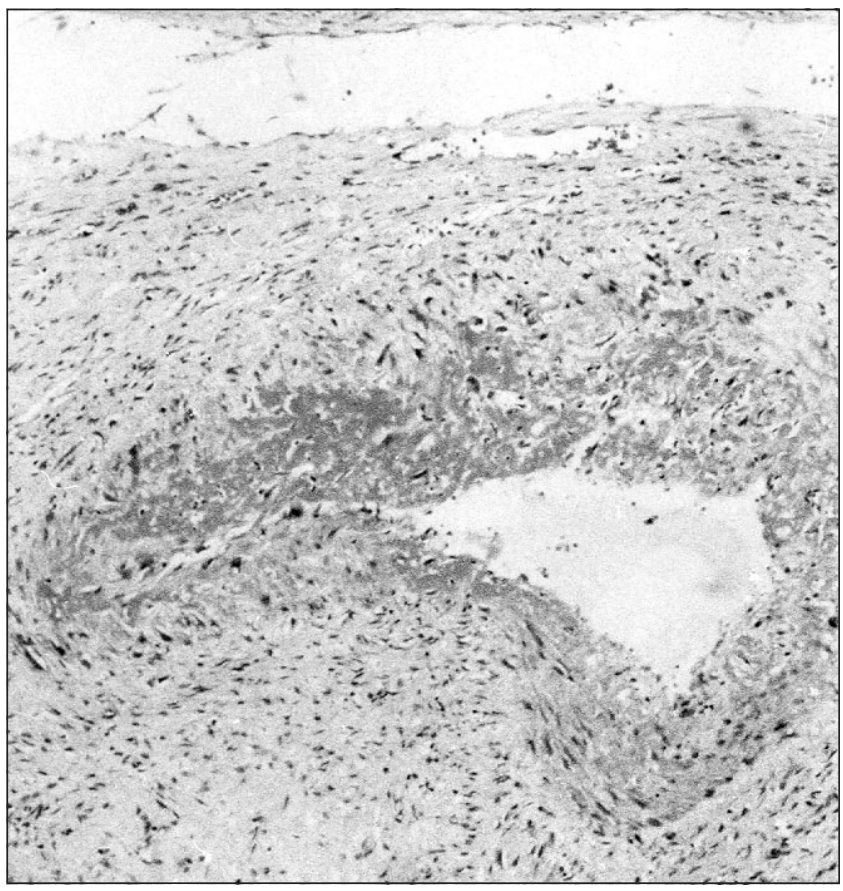

Figure 3) Necrotizing arteritis of a large muscular pancreatic artery (hematoxylin and eosin, original magnification $\times 240$ )

were clearly present. There were, however, more typical areas of arterial inflammation and granulomas. Uner et al (3) have recently described a series of 16 cases of a BOOP-like variant of Wegener's granulomatosis. Though their biopsies showed a necrotizing vasculitis and at least focal parenchymal granulomatous inflammation, the major histological finding was BOOP-like fibrosis. The authors noted that while $\mathrm{BOOP}$ is often found on the periphery of unrelated lesions such as tumors, infarcts and granulomas, it was unusual for BOOP to be the principal histological finding on the lung biopsy specimens of the 16 cases of Wegener's granulomatosis (3).

Our case report and the reports and series described suggest the existence of a BOOP-vasculitic syndrome. Moreover, our patient and that of Robinson and Sterrett (1) rapidly progressed from BOOP to ARDS and respiratory failure. Had an association between BOOP and vasculitis been more clearly defined, we might have treated our patient more aggressively with cyclophosphamide or searched further for evidence of vasculitis upon finding evidence for BOOP in our patient's open lung biopsy. We hope that knowledge of this association will aid in the management of future patients.

\section{REFERENCES}

1. Robinson BWS, Sterrett G. Bronchiolitis obliterans associated with polyarteritis nodosa. Chest 1992;102:309-11.

2. Ludmerer KM, Kissane JM. Renal failure and a resolving pulmonary nodule in a 69-year-old woman. Am J Med 1992;92:315-26.

3. Uner AH, Rozum-Slota B, Katzenstein A-L. Bronchiolitis obliteransorganizing pneumonia (BOOP)-like variant of Wegener's granulomatosis: A clinicopatholocic study of 16 cases. Am J Surg Pathol 1996;20:794-801.

4. Epler GR, Colby TV, McLoud TC, Carrington CB, Gaensler EA. Bronchiolitis obliterans organizing pneumonia. N Engl J Med 1985;312:152-8 


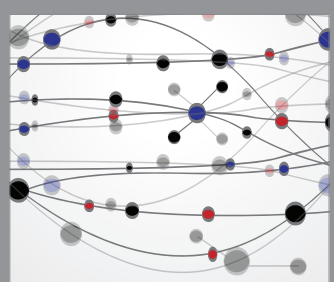

The Scientific World Journal
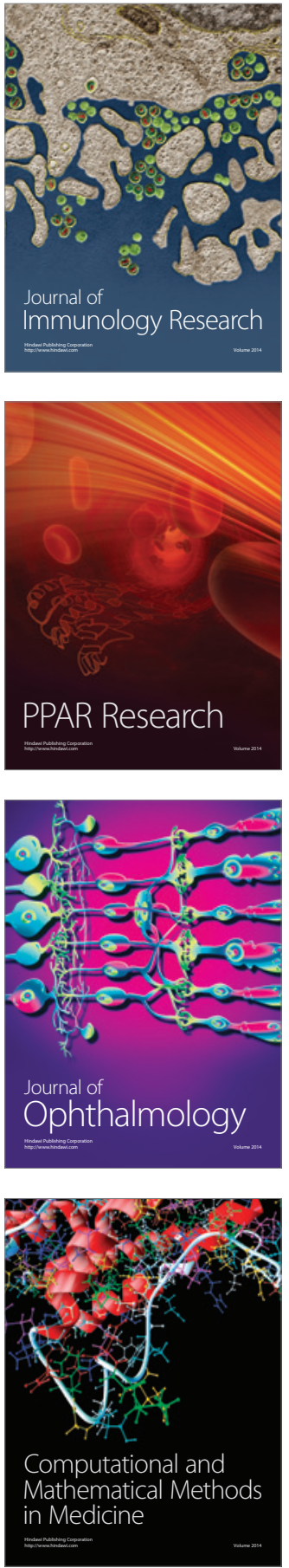

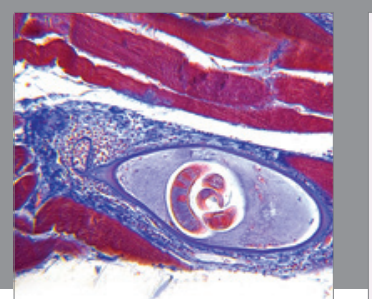

Gastroenterology Research and Practice

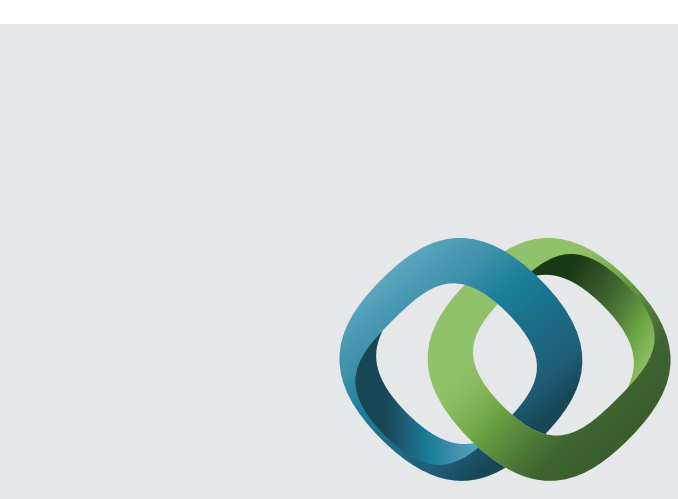

\section{Hindawi}

Submit your manuscripts at

http://www.hindawi.com
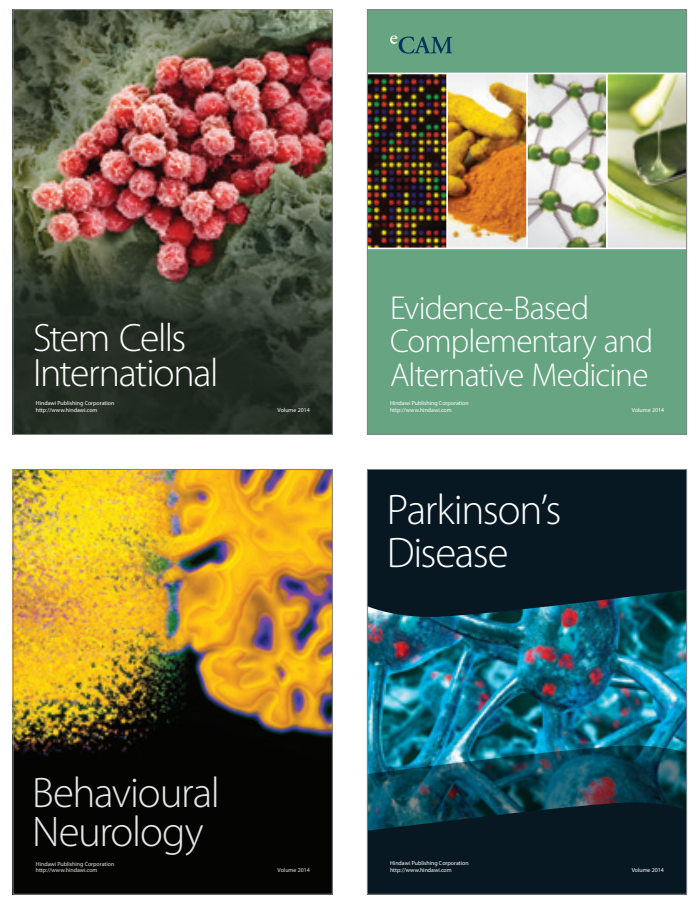
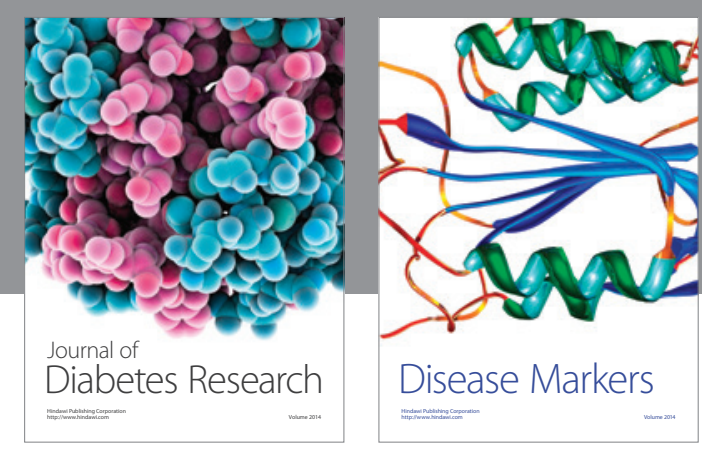

Disease Markers
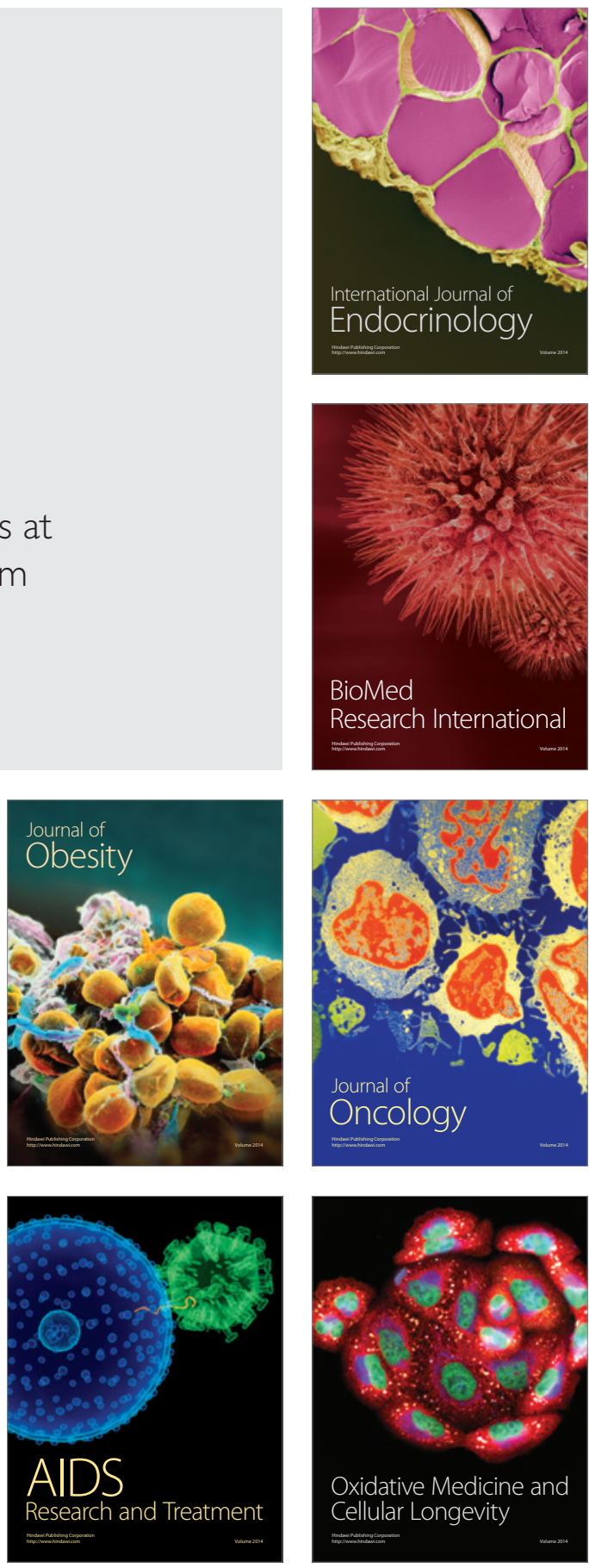